\title{
TRANSIÇÃO JURÍDICO-POLÍTICA DA PRESIDÊNCIA DA REPÚBLICA EM TEMPOS DE CRISE
}

\section{LEGAL AND POLITICAL TRANSITION OF THE PRESIDENCY OF THE REPUBLIC IN TIMES OF CRISIS}

\section{Cristiano Aparecido Quinaia ${ }^{1}$}

RESUMO: O Brasil vive um momento de grande instabilidade política, econômica e social. De forma ampla, não se trata de um fato isolado, mas, resultante de movimentos mundiais, crises de longo prazo instaladas em potências com as quais o país e a América Latina se relacionam. Nesse contexto, os brasileiros sofreram o segundo processo de impedimento de Presidente da República democraticamente eleito, que perdeu o mandato em virtude do desagrado de setores econômicos dominantes. Constata-se um movimento de retrocesso das garantias e direitos fundamentais sociais. Denúncias, investigações e ações criminais são ajuizadas em desfavor do chefe do executivo. Torna-se imperiosa a investigação por soluções que protejam a democracia em época de crise institucional entre os poderes da República.

Palavras-chave: Democracia. Eleição.
Capitalismo. Reforma.

ABSTRACT: Brazil is experiencing a period of great political, economic and social instability. Broadly, this is not an isolated fact, but, as a result of global movements, long-term crises installed in powers with which the country and Latin America relate. In this context, the Brazilians suffered the second process of impediment of democratically elected President of the Republic, who lost his mandate due to the displeasure of dominant economic sectors. There has been a move backwards from guarantees and fundamental social rights. Complaints, investigations and criminal prosecutions are filed against the Chief Executive. It is imperative to research for solutions that protect democracy in times of institutional crisis among the powers of the Republic.

Keywords: Democracy. Election. Capitalism. Reform.

1 Mestre em Direito - Sistema Constitucional de Garantia de Direitos, pelo CEUB - Centro Universitário de Bauru, Estado de São Paulo. Advogado. Email: cquinaia@gmail.com. 


\section{INTRODUÇÃO}

A história de exploração econômica dos países sul-americanos pelo capital mundial é notícia uniforme na ciência sociológica, econômica e jurídica, reconhecendo-se facilmente certo padrão de dominação pela Europa (Inglaterra, Holanda, Espanha, França) e pelos Estados Unidos durante grande espaço histórico que se estende de forma mais forte e menos visível nos dias atuais.

É que a globalização cambiante no novo século suscitou um processo de deculturação, contaminação de valores, perda e busca de identidade, logo, tornou-se menos abrupta a forma de dominação, porém, mais presente.

Vemos em Brasil a abertura irretorquível do mercado ao consumo estadunidense, a adoção do padrão fastfood, roupas, acessórios, veículos, eletrônicos, investimentos que são enviados para fora do País. O que opera é o monstruoso sistema de comunicação de massa, fazendo a cabeça das pessoas, impondo-lhes padrões de consumo inatingíveis, desejabilidades inalcançáveis. (RIBEIRO, 2016, p. 157).

Assim, a sociedade subordina-se ao mercado capitalista dominante, que transforma a realidade dos brasileiros, cria para estes necessidades, padrões e biótipos de personalidades agora publicadas em redes sociais.

Há uma perda de identidade, de independência, tanto sob o aspecto financeiro, econômico quanto cultural, que se prende ao produto e padrão estadunidense, como bem destacado por Galeano (2016, p. 17) “[...] a divisão internacional do trabalho significa que alguns países se especializam em ganhar e outros em perder".

Infelizmente, com o Brasil assim sempre ocorreu, e ocorrerá enquanto as infraestruturas sociais não se evoluírem de 
tal maneira que este modelo arcaico de Estado burguês que manipula um conceito abstrato de igualdade e legalidade seja banido por forças reais de trabalho e do proletário.

Mais confortável é afirmar que o brasileiro era o índio, o silvícola que aqui habitava antes da instalação da Coroa Portuguesa que promoveu o escambo das mercadorias e da natureza existente em solo das chamadas "índias".

O evento de deculturação, como afirma Darcy Ribeiro (2016, p. 131), foi responsável não pela troca, mas pela perda da identidade própria daquele povo selvagem que aqui habitava sem o reconhecimento de riqueza e necessidade supérflua promovida pelo capitalismo.

Desde a chegada do primeiro negro, até hoje, eles estão na luta para fugir da inferioridade que lhes foi imposta originalmente, e que é mantida através de toda a sorte de opressões, dificultando extremamente sua integração na condição de trabalhadores comuns, iguais aos outros, ou de cidadãos com os mesmos direitos. (RIBEIRO, 2016, p. 131).

O processo iniciado pela chegada dos portugueses, que usaram e abusaram dos índios, com as suas mulheres procriaram, foi continuado pela vinda de negros de variadas regiões da África escravizada, desterrada pela mão do senhor proprietário de força econômica.

Iniciou-se o processo de colonização pelo caminho inverso: Não se acrescentou, não rendeu cultura aos índios, contaminouos, retirou-lhes o caráter sagrado que mantinham em relação à natureza em prol da exploração mercadológica e industrial.

É dizer, pesou sobre esses índios o sentimento de desfazimento de seu tradicionalismo, desmerecimento, empobrecimento de autoestima, assim como o movimento promovido em relação aos negros que eram considerados coisas, objetos de relação jurídica de ordem comercial. 
O Brasil começou, então, pelo seu fim. Originou-se da concessão pelos portugueses de um nome, fruto da árvore que continha valiosa tintura para finos tecidos, o pau-brasil, seguindose a tentativa de catequização pela Igreja Católica.

Vieram os negros destituídos de personalidade jurídica, coisificados, para também aqui tomar posse de feitorias, engenhos, moinhos de açúcar e farinha, sendo explorados pelo domínio econômico europeu que predominava na época.

O Brasil se tornara um consulado lusitano, conforme afirma Darcy Ribeiro (2016, p. 331), uma terra e um conglomerado de pessoas cuja comunicação se fazia pelo lucro, pela necessidade de aceleração da produção do mercado externo.

Nós, brasileiros, nesse quadro, somos um povo em ser, impedido de sê-lo. Um povo mestiço na carne e no espírito, já que aqui a mestiçagem foi crime ou pecado. Nela fomos feitos e ainda continuamos nos fazendo. Essa massa de nativos oriundos da mestiçagem viveu por séculos sem consciência em si, afundada na ninguendade. (RIBEIRO, 2016, p. 331).

Esse fenômeno implicava, de um lado, na ausência de reconhecimento de capacidade econômica igualitária, uma liberdade burguesa, limitada aos desígnios capitalistas foi politicamente instituída.

Uma diferenciação que se impôs pelo conjunto de formação do povo brasileiro, através de negros e imigrantes que vieram a trabalho e se viram forçados a permanecer como condição de sobrevivência. Não se lhes sobejava outra opção. A formação industrial herdou do escravagismo e feudalismo as formas de discriminação social, da inferioridade e da hierarquia do poder econômico.

A chuva que irriga os centros do poder imperialista afoga os vastos subúrbios do sistema. Do mesmo modo, e simetricamente, o bem-estar de nossas classes dominantes - do- 
minantes para dentro, dominadas de fora - é a maldição de nossas multidões, condenadas a uma vida de bestas de carga. (GALEANO, 2016, p. 19).

Os povos latino-americanos, e, sobretudo, o brasileiro, serviu à hegemonia das potências mundiais, primeiro europeias, depois, estadunidense, fornecendo-lhes suas jazidas de prata, ouro, e outros minérios.

As descobertas de Colombo permitiram aos espanhóis conquistar a América, onde instalaram minas de ouro e de prata, bem como plantações de açúcar e tabaco que enriqueceram, reis, banqueiros e comerciantes espanhóis em um nível jamais sonhado. (HARARI, 2016, p. 327).

O Brasil e outros países latino-americanos se formaram, então, sob a égide da exploração capitalista, com a mão-deferro do regime que visa o lucro sobre a igualdade concreta dos indivíduos, que é indiferente à diferença étnica da formação de seu povo.

O crescimento dos centros urbanos dá lugar a uma burocracia civil e eclesiástica da mais alta hierarquia e a um comércio autônomo e risco, integrado quase exclusivamente por reinos. Naturalmente, cada patrício enriquecido quer ser patrão e cada patrão aspira às glórias de um mandato que lhe dê, além de riqueza, o poder de determinar o destino alheio. (RIBEIRO, 2016, p. 155).

O Brasil cresceu sob a aspiração da exploração do homem pelo escopo capitalista, a obtenção da vantagem sobre a vantagem, sem qualquer moral ou ética em relação à pessoa alheia.

Garante-se, por meio do falido pacto social, um mínimo de garantias em meio à guerra do capital, para que se mantenha em calmaria a massa explorada de trabalhadores que vendem sua força de trabalho.

Dentro desse contexto social jamais se puderam desenvolver instituições democráticas com base em formas locais de autogoverno. As instituições republicanas, adotadas for- 
malmente no Brasil para justificar novas formas de exercício do poder pela classe dominante, tiveram sempre como seus agentes junto ao povo a própria camada proprietária. (RIBEIRO, 2016, p. 165).

Esse fenômeno não é isolado e particular do povo brasileiro, senão é uma constatação dialética do fenômeno do capitalismo que vem assolando as sociedades há muitos séculos, celebremente estudado por Marx e seu parceiro Engels.

\section{O SEGREDO DA DEMOCRACIA E A SUPERESTRUTURA MARXISTA}

O método sociológico não é apenas um descritivo resultante de forças econômicas que Marx retratou na Europa, mas, é uma teoria sociológica de um dos grandes nomes da ciência mundial. Compreender o marxismo implica, necessariamente, e a priori, compreender a noção fundamental concebida entre sociedade e economia, entre as estruturas do poder e a superestrutura capitalista.

O que ocorre, e ocorreu no Brasil, é que a classe dominante, a elite detentora dos meios de produção, os burgueses, direciona a finalidade da sociedade de acordo ao atendimento de seus predicados.

As ideias da classe dominante são, em cada época, as ideias dominantes; isto é, a classe que é a força material dominante da sociedade é, ao mesmo tempo, sua força espiritual dominante. A classe que tem a sua disposição os meios de produção material dispõe também dos meios de produção espiritual, de modo que a ela estão submetidos aproximadamente ao mesmo tempo os pensamentos daqueles aos quais faltam os meios de produção espiritual. As ideias dominantes nada mais são que a expressão ideal das relações materiais dominantes, são as relações materiais dominantes apreendidas como ideias; portanto, são a expressão das relações que fazem de uma classe a classe dominante, são as ideias de sua dominação. (MARX, 1993, p. 72). 
Os interesses defendidos pelos representantes eleitos nem de longe se afiguram condizente com a real condição das massas populares, nem respeitam suas necessidades, mas, sim, refletem a posição econômica do interesse dominante em certa época e local.

A democracia é - ou deveria ser - a forma de governo que atende aos anseios da população, que revela com transparência os atos e decisões políticas que são tomadas e para quê são empregados os recursos públicos. Ocorre que nem sempre - e o legado dos golpes na América Latina faz jus à tese - o que se pede nas urnas é o que se revela na prática; uma coisa é pressuposta no papel e outra diversa é colocada no fato.

Aterrissamos na teoria de Norberto Bobbio que se refere ao segredo da democracia, a mão invisível, o lado oculto da moeda, a parte encoberta do poder como ele é economicamente exercitado pelas instâncias do poder contemplado no pacto social.

Não se compreende nada do nosso sistema de poder se não se está disposto a admitir que poder debaixo do governo visível há um governo que age na penumbra (o assim chamado subgoverno) e, ainda mais embaixo, um governo que age na mais absoluta obscuridade e que poderia ser chamado de criptogoverno. (BOBBIO, 2015, p. 37).

O jurista italiano refere-se, assim, às instâncias que se formam entre o poder econômico e o poder político, a forma como este se representa na prática dos governantes em representação ao modelo capitalista em voga:

Na produção social da própria existência, os homens entram em relações determinadas, necessárias, independentes da sua vontade; essas relações de produção correspondem a um grau determinado de desenvolvimento de suas forças produtivas materiais. A totalidade dessas relações de produção constitui a estrutura econômica da sociedade, a base real sobre a qual se eleva uma superestrutura jurídica e política e à qual correspondem formas sociais determina- 
das de consciência. O modo de produção da vida material condiciona o processo da vida social, política e intelectual. Não é a consciência dos homens que determina o seu ser; ao contrário, é o ser social que determina sua consciência. (MARX, 2008, p. 47).

O contrato social, assim, atende apenas ao fim do capitalismo, fazendo um feixe de promessas abstratas que são levianamente discutidas no âmbito do parlamento, porém, na prática são ocultamente dilaceradas pelo poder oculto, pela estrutura da ideologia capitalista dominante.

A concepção segundo a qual a instância econômica, sendo a base da vida social dos homens, não existe senão permeada por todos os aspectos dessa vida social, os quais, por sua vez, sob modalidades diferenciadas, são instâncias da superestrutura possuidoras de desenvolvimento autônomo relativo e influência retroativa sobre a estrutura econômica. (MARX, 2013, p. 46).

A infraestrutura, isto é, as fontes dominantes do exercício do capitalismo, sufocam a superestrutura jurídica formal que se forma acima dele, condicionando o porquê e o para quê o governo é exercido.

Afinal, os fins pelos quais o Estado em determinada época existe não é diverso senão obter um pacto que torne possível a exploração do homem pela hegemonia capitalista naquela sociedade. Estabelece, por assim dizer, uma bandeira branca, um acordo formal que esconde por detrás um teatro de manipulação de fantoches políticos.

\section{DOS EPISÓDIOS DE INSTABILIDADE À DEMOCRACIA LATINOAMERICANA}

Golpe: palavra que designa uma violência, ato de choque físico que causa lesão no adversário, indica uma reação, um ataque, um determinado ato de supremacia ou de acerto de 
uma força contra um corpo.

Ao contrário de uma revolução, que normalmente ocorre quando um grande número de pessoas se junta em prol de uma mudança social, econômica e/ou política, um golpe é uma mudança no poder do alto que simplesmente resulta na substituição abrupta de líderes do governo, como por exemplo, presidentes, reis e $1^{\circ}$ ministros. (BARBÉ, 1998, p. 545).

Consoante visto, a noção de golpe remonta ao de oligarquia, ditadores, força militar, ou, consoante temos visto, em uma força invisível, secreta, que conduz o procedimento legitimamente posto pela maioria dominante para a destituição do chefe de estado.

Quer-se dizer, nem sempre um golpe político pressupõe a coerção ou uso de força militar, pode ou não envolver ameaça de guerra civil, porém, envolve determinantemente influência no centro de poder e controle.

A lei pode ser manipulada, o procedimento por ele previsto para a cassação de direitos políticos pode ser modificado, induzido e conduzido, de tal sorte que se alcance, de forma não violenta, o resultado almejado.

Assim, o golpe político nem sempre é cruento, violento, no sentido físico da ação, pois, pode acontecer de forma mansa, misteriosa e secreta, nos corredores do Palácio do Planalto e do Congresso, onde são votadas as leis e decidido o mérito do processo de impedimento do Presidente da República.

Entre tentativas, golpes concretos cruentos e incruentos, a América Latina soma um histórico absurdo de mudanças paradigmáticas do chefe do poder, deposto por meio de forças sociais, políticas, econômica ou militar. "A expressão coup d'État ganhou, sem dúvida alguma, direito de cidadania na literatura francesa, tanto que Gabriel Naudé escrevia, já em 1639, as suas Considérations politiques surle coup d'État'. 
(BARBÉ, 1998, p. 545).

Conforme levantamento feito, no último século diversos países do continente sul-americano sofreram o desgaste do desmantelamento das forças políticas democraticamente eleitas pelo voto, em substituição a chefes de poder indicados pelo interesse econômico predominante.

1908: golpe de Estado en Venezuela. 1911: golpe de Estado en México.

1913: golpe de Estado en México.1919: golpe de Estado en Perú.

1924: golpe de Estado en Chile.1925: golpe de Estado en Chile.

1929: golpe militar en Perú.1930: golpe de Estado en Argentina.

1931: golpe de Estado en El Salvador.1931: golpe de Estado en Panamá

1932: golpe militar en Chile. 1933: golpe de Estado en Uruguay.

1936: golpe de Estado en Nicaragua.1943: golpe militar en Argentina.

1944: golpe de Estado en El Salvador. 1945: golpe de Estado en Venezuela

1947: golpe de Estado en Nicaragua.1948: golpe de Estado en Venezuela.

1948: golpe de Estado en Costa Rica.1948: golpe militar en Perú.

1948: golpe de Estado en El Salvador.1952: golpe de Estado en Cuba.

1953: golpe militar en Colombia.1954: golpe militar en Paraguay.

1955: golpe de Estado en Argentina.1956: golpe de Estado en Honduras.

1958: golpe de Estado en Venezuela.1959: rebelión militar 
revolucionaria en Cuba.1960: golpe de Estado en El Salvador.1961: golpe de Estado en El Salvador.1962: golpe militar en Perú.1963: golpe militar en Honduras.

1963: golpe militar en Perú.1963: golpe militar en República Dominicana.

1963: golpe militar en Ecuador.1963: golpe de Estado en República Dominicana.1968: golpe militar en Perú.1968: golpe militar en Panamá.

1973: golpe de Estado en Uruguay.1973 golpe de Estado en Chile.

1975: golpe militar en Perú.1976: golpe militar en Ecuador. 1976: golpe militar en Argentina.1979: golpe de Estado en El Salvador.

1980: golpe de Estado en Bolivia.1989: golpe de Estado en Paraguay.

1997: golpe de Estado en Ecuador. 2000: golpe de Estado en Ecuador.

2002: golpe de Estado en Venezuela. 2004: golpe militar en Haití.

2005: golpe de Estado en Ecuador.2009: golpe de Estado en Honduras. (Michilini, 2016, p. 15).

O Brasil, apesar de sua prematura existência como país independente, cerca de duzentos anos desde o grito do Ipiranga, soma um catálogo de ampla experiência de exposição de seu povo aos golpes da história.

Para não ir muito longe, relembrando os principais casos, podemos destacar o Estado Novo Getulista que, a despeito de ser lembrado como precursor no estabelecimento de leis do mercado de trabalho, ascendeu ao poder de forma ilegítima, imposta, como seus sucessores da Ditatura Militar.

$\mathrm{Na}$ década de 90, o $1^{\circ}$ Presidente a assumir um mandato votado democraticamente, Fernando Collor de Mello, sofreria 
o processo de impeachment deflagrado em razão da adoção de seu plano econômico que incluída o bloqueio de poupanças.

No ano de 2016, também por questões de índole econômica, discussão a respeito de tomada de decisão a respeito do orçamento público, Dilma Roussef sofreria o impeachment de seu cargo, sob forte comoção e movimento das ruas brasileiras apelando pelo reconhecimento do golpe.

Os casos de Dilma e Collor repercutem de forma curiosa uma vez que é motivo de constante controvérsia no seio jurídico, constituindo-se de grandes exemplos de golpe formal à democracia.

No Paraguai, o recente episódio (2012) envolvendo a deposição do cargo votado do Presidente Lugo desperta o olhar para a instabilidade e insegurança jurídica instalados com um regime imposto rapidamente, com a tomada do poder em prazo de três dias. (PÉREZ, 2016, p. 12).

No ano de 2009, Honduras sofreu conturbado processo de remoção do Presidente eleito Zelaya, ao qual ao final perdeu o cargo após manifestações da Suprema Corte acusando-o de crime eleitoral e a decretação de estado de sítio pelo congresso hondurenho, com comoção nas ruas e manifestação de organismos internacionais.

Para Esquivel há um grave processo em trâmite na latino-americana que coloca em risco a estabilidade do bloco do mercosul em face da União Europeia e Estados Unidos, que em nada favorece os subdesenvolvidos, mas, sim fortalece as grandes potências mundiais, como se ver pelo excerto abaixo:

Se olharmos para a história recente da América Latina, houve outras tentativas de golpe de Estado no Equador, na Bolívia e na Venezuela que vive uma situação crítica, onde a posição ganhou o parlamento e o governo de Nicolas Maduro está muito debilitado, com graves problemas 
econômicos, fundamentalmente causados pela queda do preço do petróleo, base da economia venezuelana. (ESQUIVEL, 2016, p. 04).

Veja-se que as causas e queixas dos procedimentos de deposição dos chefes de governo dos países sul-americanos que sofreram o processo e julgamento pelo impedimento não é outro senão o econômico.

Culpa-se o gestor pela trama econômica na qual inserida seu país, pelo quadro financeiro e endividamento no qual inserido que desborda dos limites de sua atuação como agente político cujas decisões estão submetidas ao crivo dos deputados e senadores.

Implica dizer, destitui-se um cargo legitimamente votado nas urnas para outro chefe colocar no seu lugar, dando forma resolutiva para um problema intrincado no qual os países subdesenvolvidos estão relacionados no imbricado negócio do mercado internacional.

Não se pode descurar que, no caso do impedimento da presidente eleita no Brasil, Dilma Roussef, a principal acusação de descumprimento de metais e da Lei de Responsabilidade Fiscal partiu da presunção de ilicitude sem que antes tivesse havido a manifestação do Tribunal de Contas da União, consoante destacou Marcelo Neves:

Antes de tudo, cabe observar que as contas do Poder Executivo em 2015 ainda não foram sequer objeto de parecer do TCU nem de decisão do Congresso Nacional, sendo possível ainda a sua aprovação pelas instâncias competentes. Além disso, da mesma natureza jurídica foram expedidos por presidentes anteriores decretos, chegando a mais de uma centena durante o segundo governo de Fernando Henrique Cardoso, em 2001, mas as contas sempre foram aprovadas pelo TCU, que apenas apontava para a necessidade de saneamento e dava recomendações. (NEVES, 2016).

É dizer, percebe-se claramente que um mesmo padrão de 
conduta pode ser valorado desta ou daquela forma, consoante a superestrutura capitalista em vigência naquela situação e o poder de negociação com os detentores dos meios de produção.

\section{DAS PROPOSTAS DE ELEIÇÕES DIRETAS E A LACUNA DO SISTEMA}

Dois golpes democráticos em menos de três décadas de constitucionalismo brasileiro enfraqueceram o sistema de representação partidária, como a representação político-partidária, o financiamento de campanhas por empresas particulares e consórcios com estatais.

É dizer, o sistema eleitoral sofreu a influência e contaminação do código ter/não-ter do sistema econômico, para ascender à representatividade apenas candidatos congressistas que atendam aos pressupostos dos interesses do grupo econômico.

Chocam-se duas grandes forças: A econômica e a jurídica. De um lado, o suposto livre mercado (a velha mão livre da teoria econômica) controla as instâncias do poder de ascensão e seleciona os candidatos que serão patrocinados. Por outro lado, ergue-se a espada da justiça (cega) cuja lâmina se desfere em relação a qualquer indivíduo que descumpra o código lícito/ilícito. Caminhamos sobre a observação levantada por Marcelo Neves, no sentido de que vivemos em nossa sociedade em um combate entre Themis e Leviatã. A figura mítica da deusa da justiça e de outro o monstro estatal que tudo e todos pretendem controlar, pelo que se destaca:

A dimensão sistêmica é reduzida à instrumentalidade política e econômica do direito; a autonomia do direito perante os meios poder e dinheiro resulta de sua fundamentação racional discursiva, com outras palavras, de sua racionalidade procedimental. (NEVES, 2006, p. 94).

É dizer, não se pode tornar o sistema eleitoral como mero 
procedimento de validação jurídica da interferência da economia no universo de validade jurídica, olvidando-se à dominação e irritação dos influxos econômicos na tomada de decisão político-jurídico.

Ou seja, o fato de o direito operar sobre a condição lícito/ ilícito não afasta a necessidade de validação das decisões tomadas a partir de seu procedimento que não podem ter o condão de validar sua usurpação pelo capitalismo.

É nesse ponto que a Constituição aparece como uma ponte estrutural, um acoplamento que liga o mundo político e seus influxos econômicos com o mundo jurídico como um documento supremo que protege os interesses fundamentais da sociedade. Ela (a Constituição) impede a luta desesperada pelo poder, controla o procedimento de ascensão até ele e zela pela moralidade pública a partir de um conjunto de regras e princípios de limitação e transparência do poder econômico.

"Nessa acepção estritamente moderna, a Constituição pode ser apreendida como uma limitação jurídica ao governo, a antítese do regime arbitrário (constitucionalismo)". (NEVES, 2006, p. 96).

A Constituição não se encerra em um momento de outorga de seu texto. Ela é um texto vivo e forte, protege a sociedade em face do abuso e protege-se também em face de qualquer ataque ao regime democrático. Em relação à sociedade, a Constituição mostra uma instrumentalidade material porque contém em seu texto, direitos e garantias fundamentais inafastáveis e insofismáveis em face de qualquer detentor do poder.

Já em face de si mesma a Constituição carrega preceitos fundamentais que não admitem o toque pelo detentor do poder, contra qualquer empreitada no sentido de reduzir o espectro de sua abrangência.

A Constituição contém, assim, um núcleo irretorquível que 
não comporta toque pelo poder de reforma pela iniciativa dos congressistas ou da presidência da república, dispostas no $\S 4^{\circ}$ do art. 60. Em outras situações, a Constituição impede a reforma de seu texto quando a sociedade esteja acometida por crises temporárias, como estado de sítio e estado de defesa, conforme dispõe o $\S 1^{\circ}$ do art. 60. A Constituição fixou hipóteses nas quais considera que a situação de crise institucional instalada impede a saudável discussão do texto, colocando em risco sua estabilidade e segurança.

São situações nas quais a tensão entre o sistema econômico e o político suscita que a Têmis faça o controle e equilíbrio colocando em compartimentos estanques o problema da crise e o prejuízo ao funcionamento do código lícito/ilícito.

Não se trata apenas de uma fórmula para domesticar ou domar o Leviatã. Antes, o problema consiste em estabelecer, apesar das tensões e conflitos, uma relação construtiva entre Têmis e Leviatã, de tal maneira que o direito não se mantenha como uma mera abstração e o poder político não se torne imponente por sua hipertrofia ou falta de referência legitimadora. (NEVES, 2006, p. XIX).

$\mathrm{O}$ ponto que nos toca na atualidade diz respeito à referência legitimadora das forças em ascendência diante da crise instalada no País: De um lado argumenta-se pela aplicabilidade do disposto no art. 81 da Constituição Federal que consagra as eleições indiretas. No outro lado tentam-se em toque de caixa processar perante o Congresso Nacional a emenda constitucional com a finalidade de instituir a eleição direta presidencial.

As questões que se levantam são: É possível que após a cassação de mandato por impeachment sobrevenha uma emenda constitucional? Há estabilidade para isso? Para responder essa questão é preciso reconhecer que o Congresso Nacional brasileiro atual conta com 49 congressistas envolvidos em investigação criminal. (STF, Inquérito 4170). 
Depois, o Ministro Edson Fachin do Supremo Tribunal Federal aumentou essa lista, para dar sequência na investigação 8 ministros, 3 governadores, 24 senadores e 39 deputados. (FACHIN, 2017).

Essa tensão entre o jurídico e político implica no enfraquecimento da função constitucional da emenda constitucional que será votada no Congresso Nacional, colocando em dúvida a finalidade de escamotear sua integridade para favorecer forças reativas. Expliquemos.

A votação de emenda constitucional em tempos de grande crise de legitimidade do poder legislativo dado o envolvimento de grande parte de seus membros em esquemas de favorecimento na votação de leis conduz que seu objetivo pode ser ascender ao poder algum outro interesse econômico ora dominante.

Se a Constituição Federal veda a discussão de emenda constitucional em período de instabilidade institucional, por maior razão, a proposta de reforma política nessa sofreguidão prejudica sua legitimidade para se imiscuir em tão importante garantia das pessoas que é a democracia.

Em discussão temos dois procedimentos especiais de emenda à Constituição: PEC 227/2016 da Câmara dos Deputados e PEC 67/2016 do Senado, ambas têm como objetivo modificar a redação do art. 81 da Constituição Federal para impor a eleição direta como regra de transição caso haja vacância do cargo de Presidência da República.

A proposta do Senado tem como objeto fixar que, em havendo vacância nos três primeiros anos do mandato, far-se-á eleição direta. Já na Câmara a proposta aumenta para três anos e meio, deixando para a eleição indireta apenas aplicável no caso de vacância no último semestre do mandato.

Além da inviabilidade institucional, haveria outro em- 
pecilho. Em caso de aprovação, essa emenda constitucional modifica o sistema eleitoral e, por expressa previsão na Constituição vigorará apenas no próximo pleito: “Art. 16. A lei que alterar o processo eleitoral entrará em vigor na data de sua publicação, não se aplicando à eleição que ocorra até um ano da data de sua vigência”.

No Tribunal Superior Eleitoral tramita a Ação de impugnação de mandato eletivo n. 761 e ação de investigação da justiça eleitoral n. 194358 em desfavor da chapa Dilma/Temer das eleições de 2.014 foram julgadas improcedentes, mantendo-se a chapa eleita no poder, conforme decisão tomada por maioria, sendo que, o voto que abriu superou o empate foi proferido pelo Ministro Gilmar Mendes, destacando em seu voto:

Não é algum fricote processualista que se quer proteger, mas o equilíbrio do mandato. Não se substitui um presidente a toda a hora, mesmo que se queira. A Constituição valoriza a soberania popular, a despeito do valor das nossas decisões.

Se a ação fosse julgada procedente a consequência seria cassação - efeito desconstitutivo da sentença - que torna nula a diplomação da chapa que saiu vencedora nas eleições presidenciais.

De acordo com a atual redação do Código Eleitoral caso ocorra a cassação judicial do diploma, dispõe o $\S 4^{\circ}$ do art. 224 que: "A eleição a que se refere o $\S 3^{\circ}$ correrá à expensas da Justiça Eleitoral e será: I - indireta, se a vacância do cargo ocorrer a menos de seis meses do final do mandato; II - direta, nos demais casos".

A redação foi dada pela Lei n. 13.165/2015 a qual pende de apreciação de compatibilidade constitucional por meio da ADI 5507 ajuizada perante o Supremo Tribunal Federal. A ação pede a declaração de inconstitucionalidade da regra inserida pela lei a respeito da competência para julgar as ações. 
Não há efeito suspensivo e nem questionamento a respeito da modificação do processo, mas, sim verdadeira disciplina do procedimento a ser empregado em caso de aprovação da lei, o que é permitido pela Constituição Federal: "Art. 24. Compete à União, aos Estados e ao Distrito Federal legislar concorrentemente sobre: XI - procedimentos em matéria processual".

De tal sorte, a decisão do TSE, de tal maneira, também evitou maior instabilidade política, porque não havia solução lídima para a situação de cassação e transição de mandato eletivo presidencial.

\section{CONCLUSÃO}

A título de encerramento, afere-se que a afirmação de que o Brasil sofre um golpe e trauma na representação democrática é conclusão forçosa pela constatação de fato dos intentos capitalistas das medidas do governo.

Derrui-se o arquétipo de condições sociais criadas ao longo de décadas de defesa da classe trabalhadora, minorias e grupos vulneráveis em face da classe burguesa.

Por um lado, esse fato revela uma tendência da América Latina de ser explorada e neocolonizada pelo capitalismo extrativista dos Estados Unidos que ainda detém o poder acionário de grande parte de empresas mundiais.

O governo em voga no Brasil não apenas é ilegítimo em face da circunstância política da transição maculada pela interrupção do processo democrático, como também, se mostra ilegítimo em face do retrocesso social que promove com relação às dimensões dos direitos sociais até então alcançados.

O sistema jurídico-político brasileiro, no entanto, não oferece resposta jurígena para uma pronta solução. O que se vê é um emaranhando de investigações e decisões vazias, que não 
conduzem ao restabelecimento da democracia.

Urge a realização de uma reforma política que não torne os demais poderes reféns da Presidência da República e a teia de dominação elítica e econômica formada em torno dela.

A situação atual revelou que o presidencialismo de coalização formado torna viciada a votação da Câmara dos Deputados de qualquer processo instaurado em desfavor do Presidente da República.

Na prática, grande parte dos envolvidos nas investigações é congressista, tornando o julgamento pela Câmara absolutamente viciado e parcial, no que se arrastam as ilegalidades e retrocessos perpetrados em face dos direitos e garantias sociais.

A Suprema Corte do país fica de joelhos, impossibilitada de levar adiante a ação penal contra o Presidente da República à luz dos escândalos que tem sido divulgado, porque a Câmara dos Deputados não autoriza e não autorizará qualquer procedimento penal que também possa comprometer seus membros e o grupo formado.

Em um sistema que preza pela democracia, a transparência e a investigação são imprescindíveis para assegurar a supremacia da Constituição e do interesse público, razão pela qual se faz necessária a reforma política a fim de que seja eliminada a sobreposição da Câmara dos Deputados ao poder jurisdicional outorgado ao Supremo Tribunal Federal no que tange às investigações de infração penal praticadas pelo Presidente da República.

Do mesmo modo, deve ser estabelecida a regra de eleições diretas quando haja a perda do cargo pelo Chefe do Executivo, suprindo a lacuna atual do ordenamento jurídico que conduz à incertezas. 


\section{REFERÊNCIAS}

ALARCÓN, Pietro. Reflexões sobre o ensino jurídico, as intenções constitucionais e a escola sem partido. Disponível em: <http://emporiododireito.com.br/reflexoes-sobreo-ensino-juridico-as-intencoes-constitucionais-e-a-escola-sem-partido-por-pietro-dejesus-lora-alarcon/>. Acesso em: 22 mar. 2017.

ALARCÓN, Pietro de Jesús. Ciência política, estado e direito público. São Paulo: Verbatim, 2011.

BARBÉ, Carlos. Golpe de Estado. In: Dicionário de política. Universidade de Brasília, 1998, p. 545-547.

BITTAR, Eduardo. Direito, sociedade e economia. Leituras marxistas. (Coord.). Barueri: Manole, 2005.

BOBBIO, Norberto. Democracia e segredo. São Paulo: Editora Unesp, 2015.

BRASIL. Supremo Tribunal Federal. Inquérito penal n. 4170. Brasília: Procuradoria Geral da República.

ENGELS, Friedrich. Do socialismo utópico ao socialismo científico. São Paulo: Edipro, 2011.

ESQUIVEL, Adolfo Pérez. Golpe é parte de um projeto de recolonização da América Latina. PROEALC, n. 72, p. 3-7, abr./maio/jun. 2016.

FACHIN, A lista de. Operação lava-jato. Disponível em: <http://g1.globo.com/politica/operacao-lava-jato/noticia/a-lista-de-fachin.ghtml>. Acesso em: 6 jun. 2017.

FOUCAULT, Michel. Vigiar e punir. Petrópolis: Editora Vozes, 2004.

GALEANO, Eduardo. As veias da América Latina. Porto Alegre: L\&M Pocket, 2016.

HARARI, YuvalNoah. Uma breve história da humanidade. 19. ed. Rio Grande do Sul: LP\&M, 2016.

MARX, Karl. A ideologia alemã. 9. ed. São Paulo: Hucitec, 1993.

MARX, Karl. Contribuição a crítica da economia política. 2. ed. São Paulo: Expressão Popular, 2008.

MARX, Karl. O capital. São Paulo: Editorial Boitempo, 2013.

Michilini, Jose Antonio. Derechos humanos en latianoamerica. Buenos Aires, 2016, p. 15-18. Disponível em: <https://dialnet.unirioja.es/descarga/articulo/5856435.pdf >. Acesso em: 14 abr. 2018.

NEVES, Marcelo. Conspiração midiático-parlamentar-judicial trama golpe contra a Presidenta, originalmente sob a liderança de um gângster. Disponível em: <http:// www.criticaconstitucional.com.br/conspiracao-midiatico-parlamentar-judicial-tramagolpe-contra-a-presidenta-originalmente-sob-a-lideranca-de-um-gangster/>. Acesso em: 19 mar. 2017.

NEVES, Marcelo. Entre Têmis e Leviatã: uma relação difícil. São Paulo: Martins Fontes, 2006.

PÉREZ, Adrián. Paraguai. Cinco anos após o massacre de Curuguaty, fala um dos seus sobreviventes: "Foi uma saraivada de tiros de metralhadora". Instituto 
Humanitas Unisinos. São Leopoldo, p. 12. 2017. Disponível em: <http://www. ihu.unisinos.br/78-noticias/568767-cinco-anos-apos-o-massacre-de-curuguaty-noparaguai-fala-um-dos-seus-sobreviventes-foi-um-tiroteio-com-metralhadoras $>$. Acesso em: 12 abr. 2018.

RIBEIRO, Darcy. O povo brasileiro. São Paulo: Editora Global, 2016.

Recebido em: 22/03/2018

Aprovado em: 30/07/2018 